\title{
The comparison analysis on electrostatic field boundary value problem solving in using avariety of algorithms
}

\author{
Wu Yifei ${ }^{\mathrm{a}}$, Zheng Weigang ${ }^{\mathrm{a}}$ \\ (School of Energy and Power Engineering ,Wuhan University of Technology ,Wuhan China \\ 430063.)
}

\begin{abstract}
Key words: Solution of electrostatic field boundary value; The finite difference method; The finite element method;

MATLAB PDE Tool; Comparative analysis
\end{abstract}

\begin{abstract}
Respectively by use of the finite difference method and based on thePDE Tool finite element method solving the analysis of rectangular metal tank boundary of electrostatic field boundary value problem, the finite difference method using a simple iteration, Gauss Seidel iterative, successive over relaxation iteration method, and discussed the solution convergence speed under different initial conditions and lateral, longitudinal comparison, and compared with PDE Tool method is based on finite element method.The results show that: In the finite difference method, successive over relaxation method in selecting the convergence factor suitable conditions, the convergence speed than other two iterative way more quickly, and the finite difference method and the finite element based PDE Tool method is used to solve the same results, but the finite element method to solve this problem more concise.
\end{abstract}

\section{Introduction}

The electrostatic field refers to the field which distribution does not change with the time, solving the static electric field has very important significance for understanding thedistribution of electromagnetic field. This kind of problem is mainly about the solution in a given area of charge distribution and potential charge distribution on the boundary, and using more intuitive way such as

image show to performance, this way called electrostatic field boundary value problem. ${ }^{[1]}$ Solving and describing boundary value in electrostatic field not only provides the research on electromagnetic field theory for complex numerical and analyticalcomputation methods, but also for practical electromagnetic modeling and simulation in engineering application to provide a basis for the optimal design problems. Many high technology and new technology based on the research of electromagnetic theory of electrostatic field, thus solving electrostatic field has rich content and practical value.Commonly used method of calculation of electromagnetic field boundary value problems mainly include two categories:The first isanalytic method, the second type is a numerical method. For those with simple boundary condition and the rules of geometry, such as rectangle, circle, available separation variable method and image analysis method, accurate analytical solutions of electromagnetic field boundary value problem. But in many practical problems often due to the boundary conditions are too complex to be obtained analytical solution, in this case, usually with the aid of the numerical solution of electromagnetic field numerical method.Numerical method mainly include finite difference method and finite element method,the two methods are in principle will be divided into continuous field limited partition, then the solution of solving 
algebraic equations, instead of solving differential and integral equation. In this paper, using finite difference method of simple iteration, Gauss Seidel iterative,successive over relaxation iteration method and the finite element method were carried outfor solving analysis, and compares the advantages and disadvantages of various methods and relevant conclusions are obtained. ${ }^{[2]}$

\section{A comparative analysis of various methods for solving}

\section{Comparison of three methods solving based onFinite difference method}

As shown in fig.1, is an infinite rectangular metal trough, Three of them are connected to the ground surface, and the rest of a plane and the three surface maintain the insulation and the potential to $\mathrm{V}=0$, the slot length and width of metal is a and $\mathrm{b}$ respectively. seek the potential distribution of the metal within the slot. ${ }^{[3]-[4]}$

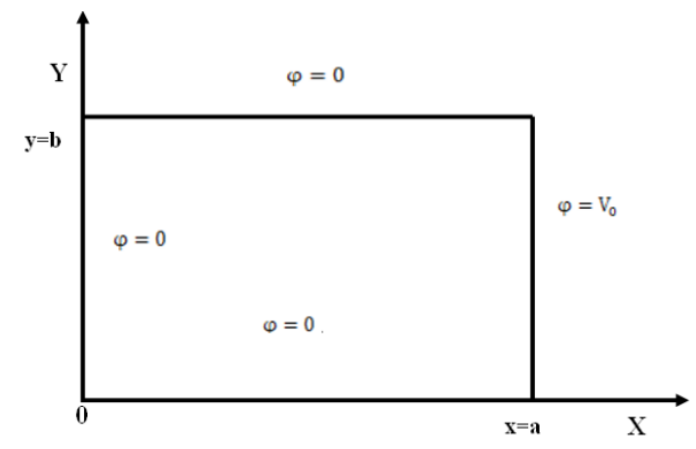

Fig.1rectangular cross section model of Metal tank

Metal trough rectangular section simplified electrostatic field grid as shown in fig.2, The following change initial assignment respectively, maximum allowable error, accelerating convergence factor and other parameters to compare, To compare by changing the initial assignment, accelerating convergence factor and changing due to maximum allowable error in the electrostatic field as shown in Figure 2 conditions. Set the $\mathrm{W}$ is the maximum permissible error,and it satisfies the following formula.

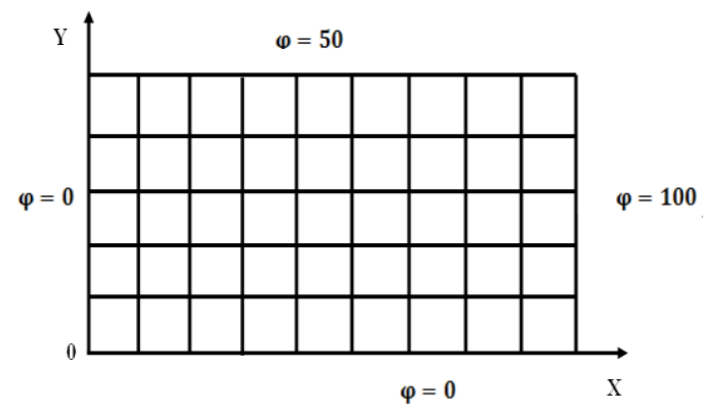

Fig.2 rectangular grid boundary of electrostatic field

$$
\left|\varphi_{i, j}^{(k+1)}-\varphi_{i, j}^{(k)}\right|<W
$$

\section{Transverse comparison}

Because of simple iterative method, gauss seidel iteration method, successive over-relaxation method based on the analysis of the influencing factors of the number of iterations in the similar way, and successive overrelaxation method contains the influential parameters, compared with other two kinds of methods to comprehensive, Therefore this paper explores the various parameters in successive overrelaxation method, the influence of the number of iterations. The calculation formula 
of successive overrelaxation method as follows: ${ }^{[5]-[6]}$

$\varphi_{i, j}^{(k+1)}=\varphi_{i, j}^{(k)}+\frac{\alpha}{4}\left(\varphi_{i+1, j}^{(k)}+\varphi_{i, j+1}^{(k)}+\varphi_{i-1, j}^{(k+1)}+\varphi_{i, j-1}^{(k+1)}-4 \varphi_{i, j}^{(k)}\right)$

By (2) compared with gauss seidel formula can get, When $a=1$, successive overrelaxation method is gauss seidel iteration method, the finite difference method is used to solve the flow diagram is shown in fig. 3 .

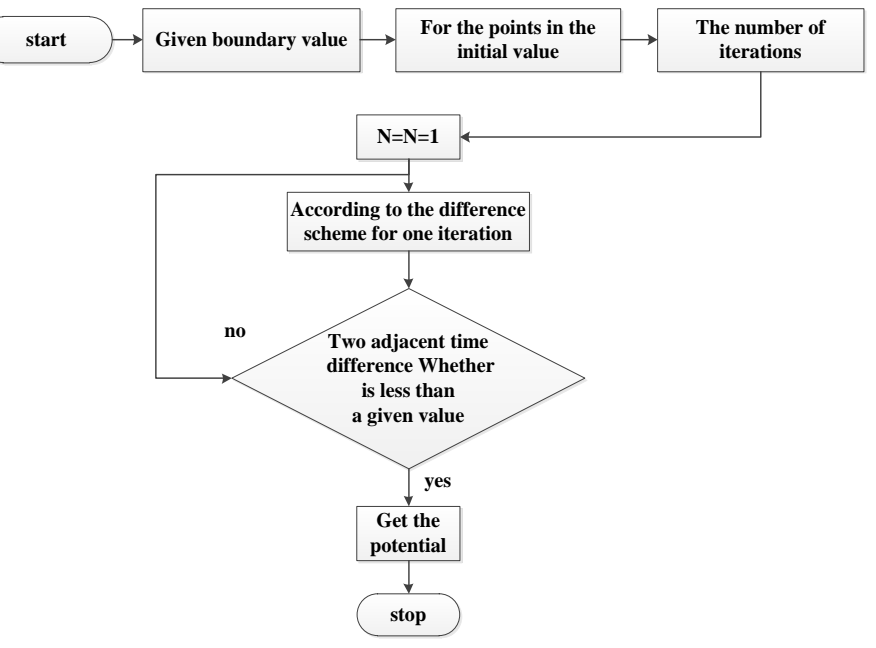

Fig.3Solution flow chart

(1). When the initial assignment different, other things being equal, the program code for:

hx=10; hy=6; v1=ones(hy,hx); v1(hy,:)=zeros $(1, \mathrm{hx})$;

$\mathrm{v} 1(1,:)=$ ones $(1, \mathrm{hx}) * 50 ; \mathrm{v} 1(:, 1)=$ zeros $(\mathrm{hy}, 1) ; \mathrm{v} 1(: \mathrm{hx})=\mathrm{ones}(\mathrm{hy}, 1) * 100 ; \mathrm{v} \quad \mathrm{v} 2=\mathrm{v} 1 ; \max \mathrm{t}=1 ; \mathrm{t}=0$;

alpha $=1 ; \mathrm{k}=0$; while $(\operatorname{maxt}>5 \mathrm{e}-5) \quad \mathrm{k}=\mathrm{k}+1 \quad \operatorname{maxt}=0$;

for $\mathrm{i}=2$ :hy-1 for $\mathrm{j}=2: \mathrm{hx}-1$

$v 2(i, j)=v 1(i, j)+(v 1(i, j+1)+v 1(i+1, j)+v 2(i-1, j)+v 2(i, j-1)-4 * v 1(i, j)) * a l p h a / 4 ;$

$\mathrm{t}=\operatorname{abs}(\mathrm{v} 2(\mathrm{i}, \mathrm{j})-\mathrm{v} 1(\mathrm{i}, \mathrm{j}))$; if $(\mathrm{t}>\operatorname{maxt}) \max =\mathrm{t}$;end end end $\mathrm{v} 1=\mathrm{v} 2$; v2end

Program calculation results are shown in table 1, by the data in the table is easy to see that the initial assignment is different, the final number of iterations. The boundary conditions in the initial value will be around 33 minimum number of iterations. 
Table 1 The calculation results under different assignment

\begin{tabular}{|l|l|l|l|l|}
\hline \multicolumn{2}{|l|}{ node initial value } & $\begin{array}{l}\text { number } \\
\text { of } \\
\text { iteratio } \\
\text { ns }\end{array}$ & Margin of error \\
\hline $\begin{array}{l}|l| \\
\text { V1(2, }\end{array}$ & $\begin{array}{l}\text { V1( } \\
2,3)\end{array}$ & $\begin{array}{l}\text { V1( } \\
2,4)\end{array}$ & K & W \\
\hline 1 & 1 & 1 & 48 & $\begin{array}{l}4.76322300571041 \\
5 \mathrm{e}-05\end{array}$ \\
\hline 10 & 10 & 10 & 47 & $\begin{array}{l}4.48253628135830 \\
7 \mathrm{e}-05\end{array}$ \\
\hline 30 & 30 & 30 & 40 & $\begin{array}{l}3.91002491966219 \\
2 \mathrm{e}-05\end{array}$ \\
\hline 33 & 33 & 33 & 28 & $\begin{array}{l}3.79972558377517 \\
1 \mathrm{e}-05\end{array}$ \\
\hline 35 & 35 & 35 & 38 & $\begin{array}{l}4.20418589612836 \\
5 \mathrm{e}-05\end{array}$ \\
\hline 40 & 40 & 40 & 43 & $\begin{array}{l}3.93477382658602 \\
4 \mathrm{e}-05\end{array}$ \\
\hline 50 & 50 & 50 & 46 & $\begin{array}{l}4.29782100042075 \\
4 \mathrm{e}-05\end{array}$ \\
\hline 100 & 100 & 100 & 51 & $\begin{array}{l}4.43927717377334 \\
8 \mathrm{e}-05\end{array}$ \\
\hline
\end{tabular}

(2). When the maximum allowable error is different, other things being equal, the program code for:

hx=10;hy=6;v1=zeros(hy,hx); 1 (hy,:)=zeros $(1, h x)$;

$\mathrm{v} 1(1,:)=$ ones $(1, \mathrm{hx}) * 50$;

v1(:,1)=zeros(hy, 1$)$;

$\mathrm{v} 1(:, \mathrm{hx})=$ ones $(\mathrm{hy}, 1) * 100 ; \mathrm{v} 1 \mathrm{v} 2=\mathrm{v} 1 ; \max \mathrm{t}=1 ; \mathrm{t}=0 ;$ alpha $=1 ; \mathrm{k}=0 ;$ while $(\operatorname{maxt}>5 \mathrm{e}-5) \mathrm{k}=\mathrm{k}+1$ maxt $=0$;

for $\mathrm{i}=2: \mathrm{hy}-1$ for $\mathrm{j}=2: \mathrm{hx}-1$

$v 2(i, j)=v 1(i, j)+(v 1(i, j+1)+v 1(i+1, j)+v 2(i-1, j)+v 2(i, j-1)-4 * v 1(i, j)) * a l p h a / 4$;

$\mathrm{t}=\operatorname{abs}(\mathrm{v} 2(\mathrm{i}, \mathrm{j})-\mathrm{v} 1(\mathrm{i}, \mathrm{j}))$; if $(\mathrm{t}>\operatorname{maxt}) \max \mathrm{t}=\mathrm{t}$; end $\mathrm{v} 1=\mathrm{v} 2$;

v2 end

the results of calculation are shown in table 2,maximum differential allowed is $5 \mathrm{e}-2$, at least 23 times the number of iterations.

Table 2 The calculation results under maximum permissible error

\begin{tabular}{|r|r|r|r|r|r|r|r|r|}
\hline $\begin{array}{r}\text { W } \\
\text { (Margin } \\
\text { of error) }\end{array}$ & $\begin{array}{r}5 \mathrm{e} \\
-2\end{array}$ & $\begin{array}{r}5 \mathrm{e} \\
-3\end{array}$ & $\begin{array}{r}5 \mathrm{e} \\
-4\end{array}$ & $\begin{array}{r}5 \mathrm{e} \\
-5\end{array}$ & $\begin{array}{r}5 \mathrm{e} \\
-6\end{array}$ & $\begin{array}{r}5 \mathrm{e} \\
-7\end{array}$ & $\begin{array}{r}5 \mathrm{e} \\
-8\end{array}$ & $\begin{array}{r}5 \mathrm{e} \\
-9\end{array}$ \\
\hline $\begin{array}{c}\mathrm{K} \\
\left(\begin{array}{c}\text { iteratio } \\
\text { ns })\end{array}\right.\end{array}$ & 23 & 31 & 40 & 48 & 57 & 66 & 74 & 83 \\
\hline
\end{tabular}


(3). A different convergence factor, other things being equal, the calculation results as shown in table 3 , factor by the table it can be seen that when $\mathrm{a}=1.4$, the convergence speed is the fastest, and the scope of convergence factor is $1 \leq \mathrm{a}<1.9$.

Table3 Calculation results of different convergence factor

\begin{tabular}{|l|l|l|l|l|l|l|l|l|l|l|}
\hline $\begin{array}{l}\text { A (Conve } \\
\text { rgenc } \\
\text { factor ) }\end{array}$ & 1 & 1. & 1. & 1. & 1. & 1. & 1. & 1. & 1. & 1. \\
K & 4 & 4 & 3 & 2 & 2 & 2 & 3 & 4 & 6 & 9 \\
$\begin{array}{l}\text { ( num } \\
\text { ber of } \\
\text { iteration } \\
\text { s })\end{array}$ & 8 & 0 & 2 & 4 & 0 & 5 & 3 & 3 & 8 & 8 \\
\hline
\end{tabular}

\section{Longitudinal comparison}

Here under the condition of the same parameters using a simple iterative method, gauss seidel iteration method, successive over-relaxation method these three ways respectively to draw the corresponding number of iterations.Set the initial value is zero, the maximum permissible error is , Because by the crosswise comparison obtained the convergence factor in the successive overrelaxation method under the conditions of a take 1.4, convergence speed is the fastest, In order to compare the results are obvious, we used here successive overrelaxation method, convergence factor a take 1.4. The program code for $\mathrm{hx}=10 ; \mathrm{hy}=6 ; \mathrm{v} 1=\mathrm{zeros}(\mathrm{hy}, \mathrm{hx}) ; \mathrm{v} 1(\mathrm{hy},:)=\mathrm{zeros}(1, \mathrm{hx})$; $\mathrm{v} 1(1,:)=\operatorname{ones}(1, \mathrm{hx}) * 50 ; \mathrm{v} 1(:, 1)=\mathrm{zeros}(\mathrm{hy}, 1) ; \mathrm{v} 1(: \mathrm{hx})=\mathrm{ones}(\mathrm{hy}, 1) * 100 ; \mathrm{v} 2=\mathrm{v} 1 ; \operatorname{maxt}=1 ; \mathrm{t}=0$; alpha $=1.4 ; \mathrm{k}=0$; while $(\operatorname{maxt}>5 \mathrm{e}-5) \mathrm{k}=\mathrm{k}+1 \operatorname{maxt}=0$; for $\mathrm{i}=2$ :hy-1 for $\mathrm{j}=2: \mathrm{hx}-1$

$v 2(i, j)=v 1(i, j)+(v 1(i, j+1)+v 1(i+1, j)+v 2(i-1, j)+v 2(i, j-1)-4 * v 1(i, j)) * a l p h a / 4$; $\mathrm{t}=\operatorname{abs}(\mathrm{v} 2(\mathrm{i}, \mathrm{j})-\mathrm{v} 1(\mathrm{i}, \mathrm{j})) ; \mathrm{if}(\mathrm{t}>\max \mathrm{t}) \max \mathrm{t}=\mathrm{t}$;endend endv $1=\mathrm{v} 2 ; \mathrm{v} 2$ end

The calculation results as shown in table 4, The parameters in the same conditions, the successive over relaxation method in selecting the convergence factor suitable conditions, the convergence speed is significantly better than the other two methods are much faster.

Tab.4 Comparison of different iterative method

\begin{tabular}{|l|l|l|l|}
\hline $\begin{array}{l}\text { Iterative } \\
\text { method }\end{array}$ & $\begin{array}{l}\text { A simple } \\
\text { iterative } \\
\text { method }\end{array}$ & $\begin{array}{l}\text { Gauss-seid } \\
\text { el iterative } \\
\text { method }\end{array}$ & $\begin{array}{l}\text { uccessive } \\
\text { overrelaxa } \\
\text { tion } \\
\text { method }\end{array}$ \\
\hline $\begin{array}{l}\text { number of } \\
\text { iterations }\end{array}$ & 88 & 48 & $\mathbf{2 0}$ \\
\hline
\end{tabular}

\section{The equipotential chart of finite difference method}

In the MATLAB environment, using the finite difference method of successive overrelaxation iteration way equipotential chart as shown in figure 4,by the equipotential chart can be seen that left boundary potential lowest,and increasing potential similar wave from the lower left corner to the upper left corner,internal electric potential gradient is more sparse, the border electric potential gradient is more intensive. 


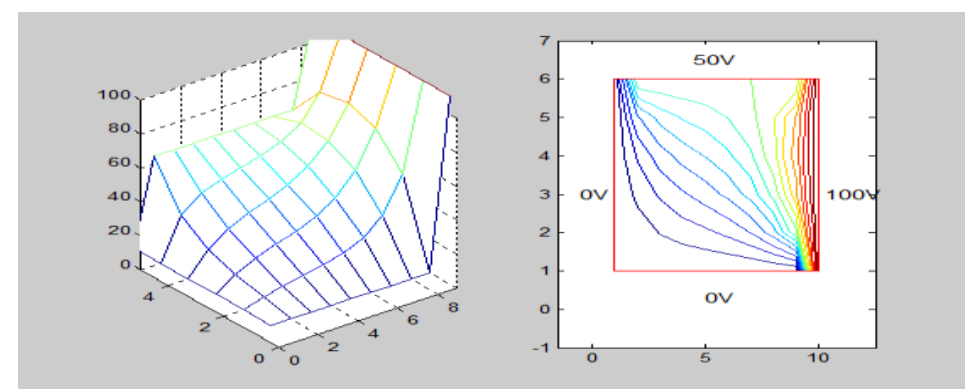

Fig.4equipotential line maps of the finite difference method

\section{Based on the finite element analysis of MATLAB PDE Tool}

The MATLAB PDE based on finite element method of Tool drawings of the equipotential chart shown in fig.5, the same as with super relaxation method to draw the equipotential chart, by the contour plot can be seen that under the left boundary, the boundary potential is low, the right potential was highest, upper second, and the potential by the left upper right direction similar wavy increment, wave is not special ules, internal electric potential gradient is more sparse, the border of intensive potential gradient, more visually presented rthe trend of potential distribution and its variation in the region of the given boundary conditions.

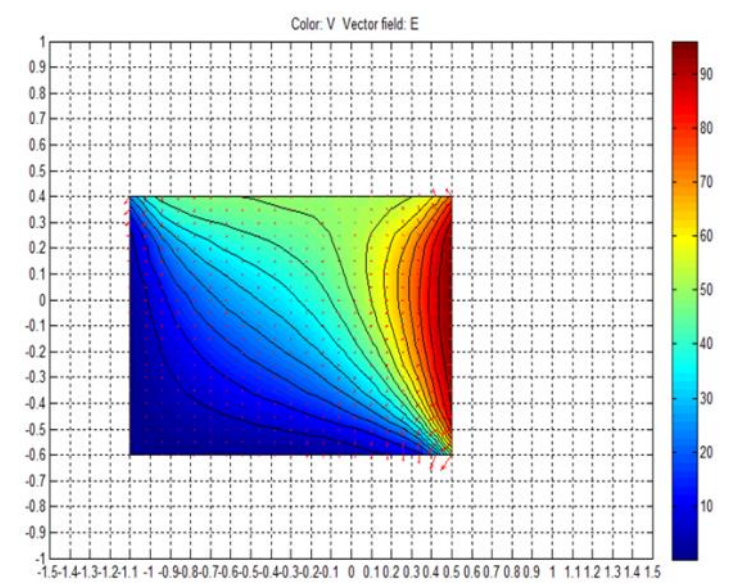

Fig.5 equipotential line maps of the finite element method

Distribution of three-dimensional rectangular boundary potentials as shown in fig.6, from the three dimensional figure can be very intuitive see potential change.The left and the underside of the potential is lower, upper and on the right side of the potential is higher, the change trend of increasing from the lower left to upper right.More visually presented boundary conditions in a given area of potential distribution and its changing trends.

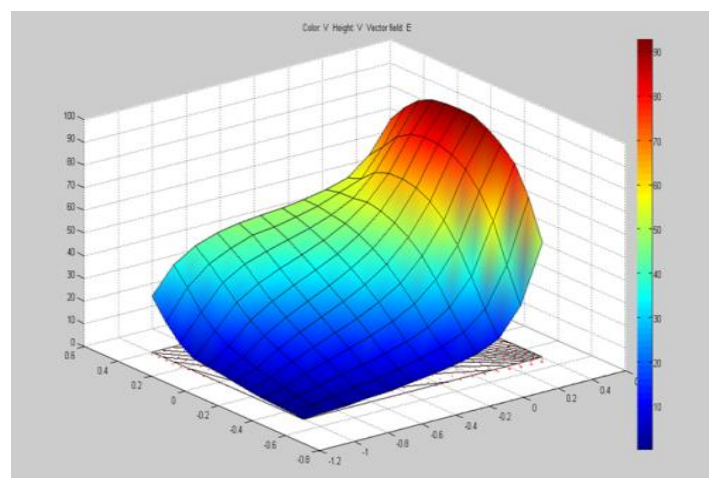

Fig.6Rectangular boundary potential distribution of three-dimensional map 


\section{Conclusion}

This article through to the metal trough rectangular boundary value problems using the finite difference method and finite element method analysis can be concluded:The same way different initial assignment or different maximum allowable error, the reservation number of iterations are not the same; The same boundary conditions, in the initial value assignment and the different reserve maximum allowable error under the same conditions using different method, the number of iterations is not the same,and successive overrelaxation method under the condition of selecting suitable accelerating convergence factor, its convergence speed obviously much faster than the other two methods,so the successive overrelaxation method is more flexible than other two methods. When the convergence factor is 1 , successive overrelaxation method is equivalent to gauss seidel iteration method.And based on the finite element method (FEM) of the PDE Tool kit involves mainly toolbox operation and use, and the results with the results of the finite difference method are basically the same, so it is easier to operate than the three finite difference relatively. At the same time, profound and extensive research on the rapid development of computerand computational electromagnetics for static electromagnetic field boundary valueproblem solving provides a powerful platform.

\section{Reference}

[1] Pan Yunxia.Solve certain boundary value problems of electrostatic field and paints[D]. Chongqing: Chongqing Normal University.2011(04).

[2] Feng Cizhang, Ma Xikui. Introduction to engineering electromagnetic field[M]. Higher Education Press.2000(06).

[3] Peng Fanglin. Visualization of MATLAB. method for solving equations of Mathematical Physics[M].Beijing: Tsinghua University press.2004(08).

[4] Zhang Guocai, Chen Hao. Solving the line charge and cylindrical conductor to form a new method of electric field [J].University Physics,2007, (7): 29-31.

[5] FEYNMAN R P. The Feynman lectures on physics(Vol. II)[M].New York: Addisorr Wesley Publishing Co, 1966:7-1, 7-2.

[6] A.T.de Hoop et al.Journal of Computational Physics 221 (2007) 88-105.

The first author: Wu Yifei (1994-),male,Wuhan University of Technology,undergraduate student, mainly study the application of electrostatic.

TEL:13797010139 E-mail:wyf20101307@163.com

Corresponding author:Zheng Weigang (1967-),male Wuhan University of Technology,technician,mainly study the application of electrostatic TEL:15391516630 E-mail:miaozhen13520@163.com 
